\title{
Cardiopulmonary resuscitation in prone position and COVID-19
}

\section{Reanimación cardiopulmonar en decúbito prono y COVID-19 \\ Lorena Díaz-Bohada (D) , Juan Camilo Segura-Salguero (D)}

Department of Anesthesiology, San Ignacio University Hospital, Pontificia Universidad Javeriana. Bogotá, Colombia.

Correspondence: Departamento de Anestesiología, Hospital Universitario San Ignacio, Pontificia Universidad Javeriana. Carrera 7 No. 40-62. Bogotá, Colombia.

Email: jldiaz@husi.org.co

How to cite this article:

Díaz-Bohada L, Segura-Salguero JC. Cardiopulmonary resuscitation in prone position and COVID-19. Colombian Journal of Anesthesiology. 2021;49:e950.

FICURE 1. Zone for cardiac decompressions and defibrillations in inverted CPR.

a.

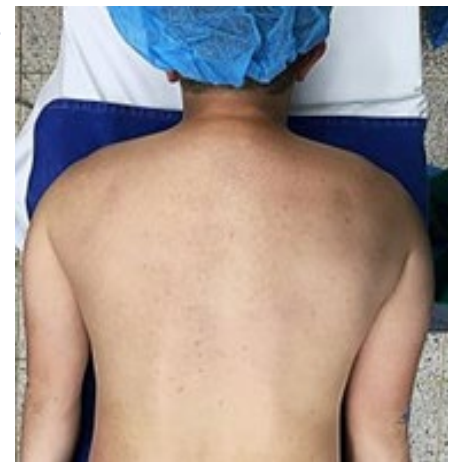

e.

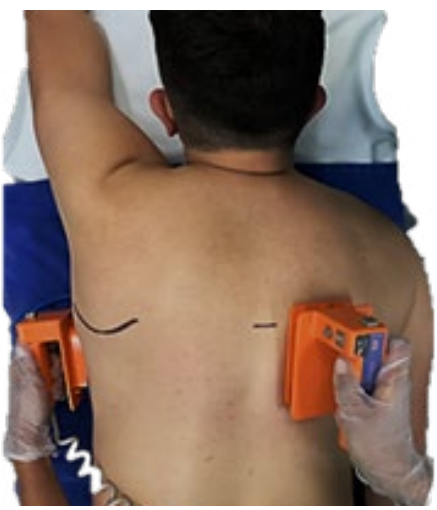

b.

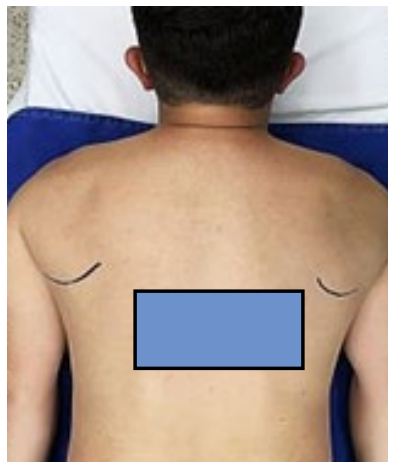

f.

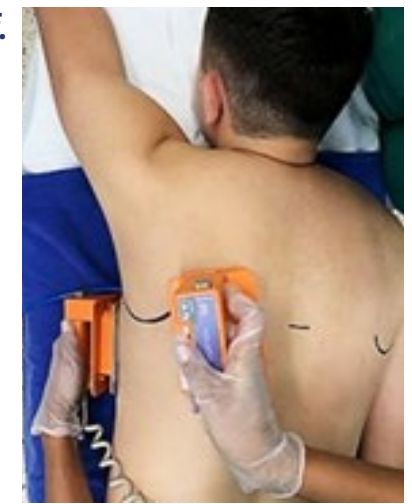

c.

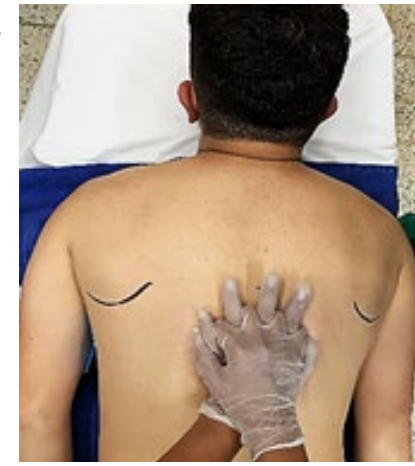

g.

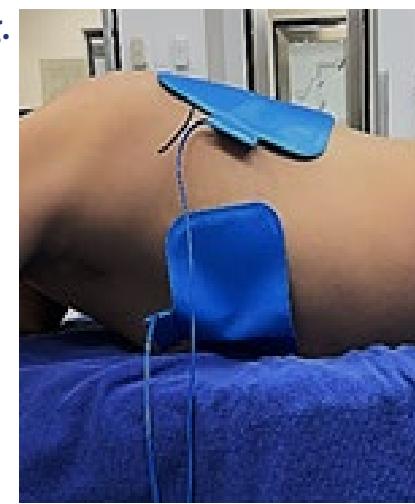

d.

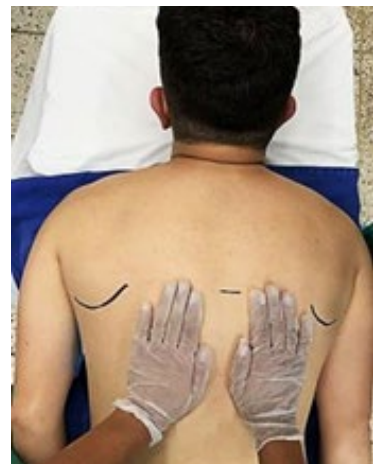

h.

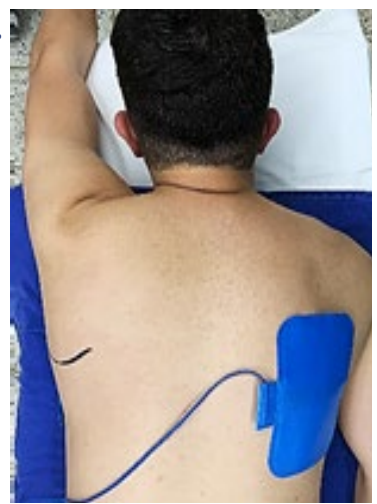

a: Patient in prone position, b: 0-2 levels below the tip of the scapula, shaded area: site to perform chest compressions, c: Compressions with hands interlocked, d: Compressions with hands apart, e-h: Position of defibrillator or patches.

SOURCE: Authors.

Patients with severe COVID-19 infection frequently require to be in prone position. (1) Furthermore, these patients with mechanical ventilation need additional vasopressor support (95.4\% vs. $1.5 \%$ ) and exhibit a higher risk of developing atrial arrhythmias (17.7\% vs. $1.9 \%$ ). (2) A study conducted in Wuhan, China, reported that $17.9 \%$ of the patients experienced intrahospital cardiac arrest; the arrest rhythms were asystole (89.7\%), pulseless electrical activity (4.4\%) and defibrillatable rhythms (5.9\%). (3) In order to reduce the hemodynamic effects secondary to changes in position (4), cardiopulmonary resuscitation (CPR) maneuvers in prone position are recommended (inverted CPR) (5); this technique was described in 1989 by McNeil, and has proven to be successful $(6,7)$ doing the inverse precordial compressions at the usual rate and amplitude. (8)

$86 \%$ of the patients have the largest left ventricular area localized between $o$ and 2 vertebral segments below the line that crosses the two inferior angles of the scapulae. In this location, the maneuver may be done as shown in Figure 1. (9) 
A pilot study suggests that this maneuver results in average systolic and mean arterial pressures higher than normal, as compared against supine RCP. This may be better explained based on a more efficient compression performed over the thoracic costovertebral junction. However, the low power of the study and the magnitude of the impact of the outcomes highlight the need for better research showing the potential benefit of inverted CPR and its complications. (10)

\section{REFERENCES}

1. Marini J], Gattinoni L. Management of COVID-19 respiratory distress. JAMA. 2020;323(22):232930. doi: http://doi.org/10.1001/jama.2020.6825.

2. Goyal P, Choi J], Pinheiro LC, Schenck E], Chen R, Jabri A, et al. Clinical characteristics of Covid-19 in New York City. N Engl ] Med. 2020;382(24):2372-4. doi: http://doi. org/10.1056/NEJMc2010419.
3. Shao F, Xu S, Ma X, Xu Z, Lyu J, Ng M, et al. In-hospital cardiac arrest outcomes among patients with COVID-19 pneumonia in Wuhan, China. Resuscitation. 2020;151:18-23. doi: https://doi.org/10.1016/i. resuscitation.2020.04.005.

4. Jozwiak M, Teboul J-L, Anguel N, Persichini R, Silva S, Chemla D, et al. Beneficial hemodynamic effects of prone positioning in patients with acute respiratory distress syndrome. Am ] RespirCritCare Med. 2013;188(12):1428-33. doi: https://doi.org/10.1164/rccm.201303-0593OC.

5. Edelson DP, Sasson C, Chan PS, Atkins DL, Aziz $\mathrm{K}$, Becker LB, et al. Interim guidance for basic and advanced life support in adults, children, and neonates with suspected or confirmed COVID-19. Circulation. 2020;141:e933-43. doi: https://doi.org/10.1161/CIRCULATIONAHA.120.047463.

6. McNeil EL. Re-evaluation of cardiopulmonary resuscitation. Resuscitation 1989;18(1):1-5. doi: https://doi.org/10.1016/0300-9572(89)90107-X.

7. Brown ], Rogers ], Soar ]. Cardiac arrest during surgery and ventilation in the prone position: a case report and systematic review. Resuscitation. 2001;50(2):233-8. doi: https://doi. org/10.1016/S0300-9572(01)00362-8.

8. Cave DM, Gazmuri R], Otto CW, Nadkarni VM, Cheng A, Brooks SC, et al. Part 7: CPR techniques and devices: 2010 American Heart Association Guidelines for Cardiopulmonary Resuscitation and Emergency Cardiovascular Care. Circulation. 2010;23(1):1-7. doi: https://doi.org/10.1161/CIRCULATIONAHA.110.970970.

9. Kwon M-J, Kim E-H, Song I-K, Lee J-H, Kim $\mathrm{H}-\mathrm{S}$, Kim J-T. Optimizing prone cardiopulmonary resuscitation. Anesth Analg. 2017;124(2):520-3. doi: https://doi.org/10.1213/ ANE. 0000000000001369 .

10. Mazer SP, Weisfeldt M, Bai D, Cardinale C, Arora R, Ma C, et al. Reverse CPR: a pilot study of CPR in the prone position. Resuscitation. 2003;57(3):279-85. doi: https://doi. org/10.1016/S0300-9572(03)00037-6. 